\title{
The clinicopathologic features of chronic active Epstein-Barr virus infective enteritis
}

\author{
Rongbei Liu ${ }^{1,2} \cdot$ Mengyu Wang ${ }^{1,2} \cdot$ Lizhi Zhang $^{3} \cdot$ Weixun Zhou ${ }^{4}$ Ying Huang ${ }^{5} \cdot$ Hong Guo $^{6} \cdot$ Yubei Gu $^{7} \cdot$ Yan Chen $^{8}$. \\ Yuqin $\mathrm{Li}^{9} \cdot$ Chunxiao Chen ${ }^{10} \cdot$ Yufang Wang ${ }^{11} \cdot$ Lan Rong $^{12} \cdot \mathrm{Ji} \mathrm{Li}^{13} \cdot$ Jiaqi Xu ${ }^{14} \cdot$ Qian $\mathrm{Cao}^{1,2} \cdot$ Zhinong Jiang $^{2,14}$
}

Received: 21 July 2018 / Revised: 18 August 2018 / Accepted: 18 August 2018 / Published online: 8 October 2018

(c) United States \& Canadian Academy of Pathology 2018

\begin{abstract}
Chronic active Epstein-Barr virus infective enteritis (CAEBV enteritis) is rare and has not been well described yet. Therefore, we reported the clinicopathologic features of 11 patients with chronic active Epstein-Barr virus infective enteritis and their differences from inflammatory bowel disease. The major clinical presentations of chronic active Epstein-Barr virus infective enteritis were intermittent fever over $39^{\circ} \mathrm{C}(100 \%)$, diarrhea (73\%), abdominal pain (64\%), lymphadenopathy (64\%), splenomegaly (64\%), and hepatomegaly (27\%). The main endoscopic findings included numerous shallow, small, and irregular ulcers, mainly involving colon and small intestine together, no cobble-like appearance, and longitudinal ulcers. Compared to inflammatory bowel disease patients, the frequency of intermittent fever, hepatomegaly, splenomegaly, lymphadenopathy, the value of C-reactive protein, and serum Epstein-Barr virus DNA (EBV DNA) were significantly higher in chronic active Epstein-Barr virus infective enteritis patients $(p<0.01)$. The histologic findings show transmural inflammation with extended lymphoid infiltration, fissuring ulcers, and intraepithelial lymphocytosis. But chronic active Epstein-Barr virus infective enteritis lacked granulomas and connective tissue changes such as neural hypertrophy and thickened muscularis mucosae. Three chronic active Epstein-Barr virus infective enteritis patients died within 5 years of disease onset, and those three patients have received total colectomy, two of them died within 1 month after surgery. In this study, clinicopathologic features have been summarized to better recognize chronic active Epstein-Barr virus infective enteritis. There are resemblances between chronic active Epstein-Barr virus infective enteritis and inflammatory bowel disease, but some symptoms, signs, and indexes like intermittent fever, hepatomegaly, splenomegaly, lymphadenopathy, and elevated C-reactive protein, Epstein-Barr virus DNA are characteristics to differentiate chronic active Epstein-Barr virus infective enteritis and inflammation. Histopathological features also help the discrimination. Serum Epstein-Barr virus DNA and intestinal tissue in situ hybridization for Epstein-Barr virus-encoded RNA are recommended to exclude chronic active Epstein-Barr virus infective enteritis.
\end{abstract}

Zhinong Jiang

3200039@zju.edu.cn

Qian Cao

caoq@zju.edu.cn

1 Department of Gastroenterology, Sir Run Run Shaw Hospital, School of Medicine, Zhejiang University, Zhejiang, China

2 Center of Inflammatory Bowel Disease, Sir Run Run Shaw Hospital, School of Medicine, Zhejiang University, Zhejiang, China

3 Department of Laboratory Medicine and Pathology, Mayo Clinic, Rochester, NY, USA

4 Department of Pathology, Peking Union Medical College Hospital, Chinese Academy of Medical Sciences, Beijing, China

5 Children's Hospital of Fudan University, Shanghai, China

6 Department of Gastroenterology, Xinqiao Hospital, Third Military Medicine University, Chongqing, China
7 Department of Gastroenterology Rui Jin Hospital, Affiliate to Shanghai Jiao Tong University, School of Medicine, Shanghai, China

8 Center for Inflammatory Bowel Disease, Department of Gastroenterology, The 2nd Affiliated Hospital, School of Medicine, Zhejiang University, Zhejiang, China

9 Department of Gastroenterology, Bethune 1st Affiliated Hospital of Jilin University, Changchun, China

10 The 1st Affiliated Hospital, School of Medicine, Zhejiang University, Zhejiang, China

11 Department of Gastroenterology, West China Hospital, Sichuan University, Chengdu, China

12 Huashan Hospital, Fudan University, Shanghai, China

13 Department of Gastroenterology, Peking Union Medical College Hospital, Beijing, China

14 Department of Pathology, Sir Run Run Shaw Hospital, School of Medicine, Zhejiang University, Zhejiang, China 


\section{Introduction}

Epstein-Barr virus (EBV) infections are usually acquired early in life and are generally asymptomatic in healthy people, where they establish a lifelong latency in target cells [1]. Epstein-Barr virus usually infects B cells and rarely targets T or NK cells in western countries, while in Asia, the disease usually involves T or NK cells, which is responsible for chronic active Epstein-Barr virus infection [2-4]. Following the primary infection, Epstein-Barr virus becomes latent and is thought to evade recognition by cytotoxic T cells and thus coexists with the host's immune system [2]. After primary infection, Epstein-Barr virus normally establishes a permanent latent state in the B lymphocytes of immunocompetent hosts, and persistent or recurrent symptoms are rare [2].

Chronic active Epstein-Barr virus infection is defined according to previously proposed criteria [5], as follows: (1) Epstein-Barr virus-related symptoms for at least 3 months; (2) an increased Epstein-Barr virus load in either the affected tissue or peripheral blood; and (3) lack of evidence of other diseases that could explain the condition. Chronic active Epstein-Barr virus infective patients often present with fever, lymphadenopathy, and splenomegaly [4]. Little is known about chronic active Epstein-Barr virus infection involving the intestine. In 2005, Joan Robinson and colleagues [6] first described a patient with chronic active Epstein-Barr virus infection who presented with an inflammatory bowel disease-like illness, and our group reported the similar cases in China in 2016 and 2017 [7, 8]. We proposed the term "chronic active Epstein-Barr virus infected enteritis with systemic symptoms" to describe this new entity because gastrointestinal symptoms were the predominant symptoms in those patients.

Chronic active Epstein-Barr virus infective enteritis is also a great mimicker of inflammatory bowel disease. Patients with inflammatory bowel disease often present with abdominal pain and diarrhea but may also have a wide variety of other symptoms such as rectal bleeding, weight loss, fever, nausea, and various extraintestinal manifestations [9]. Because chronic active Epstein-Barr virus infective enteritis is less widely recognized, most cases could be misdiagnosed as inflammatory bowel disease, leading to the relatively rarity of chronic active Epstein-Barr virus infective enteritis. It is a clinical challenge to discern whether the symptoms are attributable to Epstein-Barr virus infection or the underlying inflammatory bowel disease. The treatments for those two diseases are completely different, and misdiagnosis may lead to bad outcomes. Herein, we summarized the endoscopy, clinicopathologic features, and prognosis of 11 cases of chronic active Epstein-Barr virus infective enteritis with systemic symptoms, particularly focusing on the differences from inflammatory bowel disease, the association of treatment, and prognosis.

\section{Materials and methods}

\section{Patients}

One hundred and twenty patients who were diagnosed with intestinal disease and had Epstein-Barr virus testing done on ileocolonic mucosal biopsies or surgery samples were identified in our search of the database from June of 2015 to December of 2017, and 21 cases were positive for Epstein-Barr virus tests, including six cases of malignant lymphoma which were excluded in this study. The rest of the cases showing Epstein-Barr virus-positive intestinal inflammatory diseases were divided into four groups based on their in situ hybridization for Epstein-Barr virusencoded RNA results and symptoms: Epstein-Barr virus latent infection, Epstein-Barr virus infection without systemic symptoms, acute Epstein-Barr virus infection with systemic symptoms, and chronic active Epstein-Barr virus infection with systemic symptoms. Systemic symptoms include fever with unknown reasons, hepatomegaly, splenomegaly, or lymphadenopathy. Epstein-Barr viruspositive cells less than 2/high-power field (HPF) were thought to be Epstein-Barr virus latent infection. In our study, we focus on figuring out the features of chronic active Epstein-Barr virus infective enteritis with systemic symptoms, so the inclusion criteria are EBV-positive (more than 2/HPF) patients with systemic symptoms which last for at least 3 months, and the exclusion criteria are lymphoma, chronic active Epstein-Barr virus infection with lymphoma, and Epstein-Barr virus-positive enteritis without systemic symptoms. Taken together, 11 cases that were qualified as chronic active Epstein-Barr virus infective enteritis with systemic symptoms were included in this study. Four cases were recruited in our hospital, and seven cases were collected from seven other hospitals. Age- and gender-matched 100 inflammatory bowel disease patients were also selected as a comparison group.

Electronic medical records were reviewed for demographic, endoscopic, surgical, laboratory findings, pathological, and follow-up information. The human ethics committee of Sir Run Run Shaw hospital affiliated to Zhejiang university approved the study and all subjects gave written informed consent.

\section{Histological evaluation}

Lymphocytes and plasma cells infiltration in lamina propria, intraepithelial lymphocytes, cryptitis and crypt abscesses, granulomas, hypertrophic muscularis mucosae, and crypt 
abnormalities were carefully observed in all cases. For surgical samples, we carefully observed if there were transmural inflammation, aggregation of lymphocytes, fissuring ulcers, neural hypertrophy, and thickened muscularis mucosae.

\section{Immunohistochemistry and in situ hybridization}

Immunohistochemical stains for CD3, CD4, CD5, CD8, CD20, and CD56 were evaluated against proper internal or external controls.

The gold standard for detecting Epstein-Barr virus in biopsies is in situ hybridization for Epstein-Barr virusencoded RNA [10]. Epstein-Barr virus-encoded RNAs (Tib, Triplex International Bioscience, China) were performed according to the manufacturer's instructions. Briefly, 4- $\mu \mathrm{m}$-thick sections of the paraffin-embedded tissues were cut and spread with distilled water on slides. Then, slides were dried overnight at $37^{\circ} \mathrm{C}$, deparaffinized in toluene, and rehydrated through a series of graded ethanol. After being washed with distilled water twice and dried, slides were then incubated for $30 \mathrm{~min}$ in proteinase $\mathrm{K}$ $(1 \mu \mathrm{g} / \mathrm{mL})$, and again washed with distilled water and dried. The hybridization's solution containing the probes was applied in the tissue sections and the slides were incubated for $80 \mathrm{~min}$ at $55^{\circ} \mathrm{C}$ and then incubated overnight at $37^{\circ} \mathrm{C}$ in a humid room. The slides were then washed with a stringent wash solution (DakoCytomation) at $55{ }^{\circ} \mathrm{C}$ for 30 min. After application of alkaline-phosphatase-conjugated antibody to fluorescein isothiocyanate, the revelation was performed with the addition of the substrate 5-bromo-4chloro-3-indolyl phosphate and the colorimetric indicator nitroblue tetrazolium chloride (BCIP/NBT) combined with levamisole. The slides were then counterstained with hematoxylin, mounted, and viewed with a standard light microscope.

Positive staining was recognized as a brown color in the nucleus of cells. A known EBV-positive nasopharyngeal carcinoma was used as a positive control. Epstein-Barr virus-encoded RNA-positive cases were scored quantitatively in the area of the highest Epstein-Barr virus concentration per HPF $\left(0.2 \mathrm{~mm}^{2}\right)$ $(\times 400$ magnification).

\section{Statistics}

Student's $t$ tests and chi-squared tests were used to compare continuous and categorical variables, respectively. The statistical relationships were performed by Pearson's correlation analysis. Data were presented as mean \pm standard deviation (SD); $p$-value below 0.05 was considered statistically significant. Statistical analysis was conducted by SPSS version 16.0.

\section{Results}

\section{Clinical features}

Among the 11 chronic active Epstein-Barr virus infective enteritis patients, eight were males and three were females with a median age of 40 years (range, 11-72 years), while among inflammatory bowel disease patients, 60 were males and 40 were females with a median age of 36.4 years (range, 14-71 years).

The clinical features and laboratory findings of both chronic active Epstein-Barr virus infective enteritis and inflammatory bowel disease patients are summarized in Tables 1 and 2. Gastrointestinal symptoms were the main clinical presentation in all patients, and no significant differences were found between chronic active Epstein-Barr virus infective enteritis patients and inflammatory bowel disease patients. The systemic symptoms and signs were more often observed in chronic active Epstein-Barr virus infective enteritis patients, compared to inflammatory bowel disease patients, including intermittent fever over $39^{\circ} \mathrm{C}$ $(100 \%)$, hepatomegaly $(27 \%)$, splenomegaly $(64 \%)$, and lymphadenopathy $(64 \%)$, respectively $(p<0.01)$.

Detectable copies of Epstein-Barr virus DNA were found in all $(9 / 9,100 \%)$ chronic active Epstein-Barr virus infective enteritis (two patients did not do the test) and 17 of $75(23 \%)$ inflammatory bowel disease patients. The median values for Epstein-Barr virus (Fig. 1a) were significantly higher in chronic active Epstein-Barr virus infective enteritis patients $\left(1.9 \times 10^{6}\right.$ copies $\left./ \mathrm{mL}\right)$ compared to inflammatory bowel disease patients $\left(9.8 \times 10^{3}\right.$ copies $/ \mathrm{mL}$, 17 cases) $(p<0.01)$. Antibody to EBV viral capsid antigen (VCA) IgG was positive and EBV VCA IgM was negative in all patients tested with a conventional assay. Blood examination showed increased erythrocyte sedimentation rate (ESR) in chronic active Epstein-Barr virus infective enteritis patients. Interestingly, the rate of increased Creactive protein was comparable while the values were

Table 1 Clinical symptoms and signs of both chronic active Epstein-Barr virus infective enteritis (CAEBV) and inflammatory bowel disease (IBD) patients

\begin{tabular}{llll}
\hline & $\begin{array}{l}\text { CAEBV } \\
(N=11)\end{array}$ & $\begin{array}{l}\text { IBD } \\
(N=100)\end{array}$ & $p$-Value \\
\hline Diarrhea & $8 / 11$ & $70 / 100$ & $>0.05$ \\
Abdomen pain & $7 / 11$ & $53 / 100$ & $>0.05$ \\
Abdomen mass & $0 / 11$ & $0 / 100$ & $>0.05$ \\
Hematochezia & $4 / 11$ & $48 / 100$ & $>0.05$ \\
Intermittent fever $\left(>39^{\circ} \mathrm{C}\right)$ & $11 / 11$ & $4 / 100$ & $<0.01$ \\
Hepatomegaly & $3 / 11$ & $0 / 100$ & $<0.01$ \\
Splenomegaly & $7 / 11$ & $3 / 100$ & $<0.01$ \\
Lymphadenopathy & $7 / 11$ & $0 / 100$ & $<0.01$ \\
\hline
\end{tabular}


much higher in chronic active Epstein-Barr virus infective enteritis patients, which is opposite to the case of ESR (Fig. 1b, c).

Clinical data including colonoscopy manifestations of chronic active Epstein-Barr virus infective enteritis patients are summarized in Table 3. The major distortions were numerous shallow, small, and irregular ulcers. Colon and small intestine were more likely to be involved together. No uniform, continuous inflammation, cobble-like appearance, and longitudinal ulcers were present (Fig. 2).

\section{Histological findings}

Histological findings are summarized in Table 4. In most of the patients (8/11), increased mucosal lymphocytic infiltration was seen and occasionally lymphocytes infiltrate into the muscularis mucosae and submucosa. The infiltrating lymphocytes were small without cytological atypia (Fig. 3a). Intraepithelial lymphocytosis was observed in five

Table 2 Laboratory index of both chronic active Epstein-Barr virus infective enteritis and inflammatory bowel disease patients

\begin{tabular}{llll}
\hline & CAEBV & IBD & $p$-Value \\
\hline Increased WBC & $27 \%(N=11)$ & $21 \%(N=100)$ & $>0.05$ \\
Increased PLT & $27 \%(N=11)$ & $47 \%(N=100)$ & $>0.05$ \\
Increased CRP & $91 \%(N=11)$ & $61 \%(N=100)$ & $>0.05$ \\
Increased ESR & $100 \%(N=9)$ & $59 \%(N=94)$ & $<0.05$ \\
OB $(+)$ & $100 \%(N=11)$ & $48 \%(N=93)$ & $<0.01$ \\
EBV DNA $(+)$ & $100 \%(N=9)$ & $23 \%(N=75)$ & $<0.01$ \\
EBV IgG $(+)$ & $100 \%(N=11)$ & $96 \%(N=96)$ & $>0.05$ \\
EBV IgM $(+)$ & $0 \%(N=11)$ & $0 \%(N=96)$ & $>0.05$ \\
\hline
\end{tabular}

$C A E B V$ chronic active Epstein-Barr virus infective enteritis, $I B D$ inflammatory bowel disease, $W B C$ white blood cells, $P L T$ platelet, $C R P$ C-reactive protein, $E S R$ erythrocyte sedimentation rate, $O B$ occult blood cases (Fig. 3b). Mucosal plasma cell infiltration could be seen in all cases, but no basal plasmacytosis was observed. No granulomas were identified in all cases. We found cryptitis in three cases and occasional crypt abscesses in one case. Focal disturbed crypt architecture was observed in five cases.

In five surgical samples, transmural inflammation and aggregation of lymphocytes were observed in all five samples, although two cases only showed focal aggregation of lymphocytes (Fig. 3c). Some lymphoid aggregates were near vessels with an irregular shape. There was no bead-like lymphocyte aggregation along the outside of the intestinal muscular layer. Ulcers were seen in all samples, including three samples with fissuring ulcers (Fig. 3d). No neural hypertrophy, thickened muscularis mucosae, or abscesses were observed in those samples.

\section{In situ hybridization for Epstein-Barr virus-encoded RNA and immunohistochemistry}

The immunohistochemistry and in situ hybridization for Epstein-Barr virus-encoded RNA results are summarized in Table 4. In situ hybridization for Epstein-Barr virusencoded RNA results showed that Epstein-Barr virusencoded RNA-positive lymphocytes were more than 100/ HPF in every surgical sample (patient 1-5), 83\% (5/6) biopsy samples were more than 50/HPF, and 17\% (1/6) biopsy samples was 33/HPF. Epstein-Barr virus-encoded RNA-positive lymphocytes distributed unevenly, and were mainly found in lesional area, especially ulcers and lymphocyte-rich regions (Fig. 3e).

All 11 cases showed lymphoid infiltration in intestinal mucosa, the infiltration was composed of predominantly $\mathrm{T}$ lymphocytes in which CD4+ T cell and CD8 $+\mathrm{T}$ cell existed with a normal ratio, and only one case was
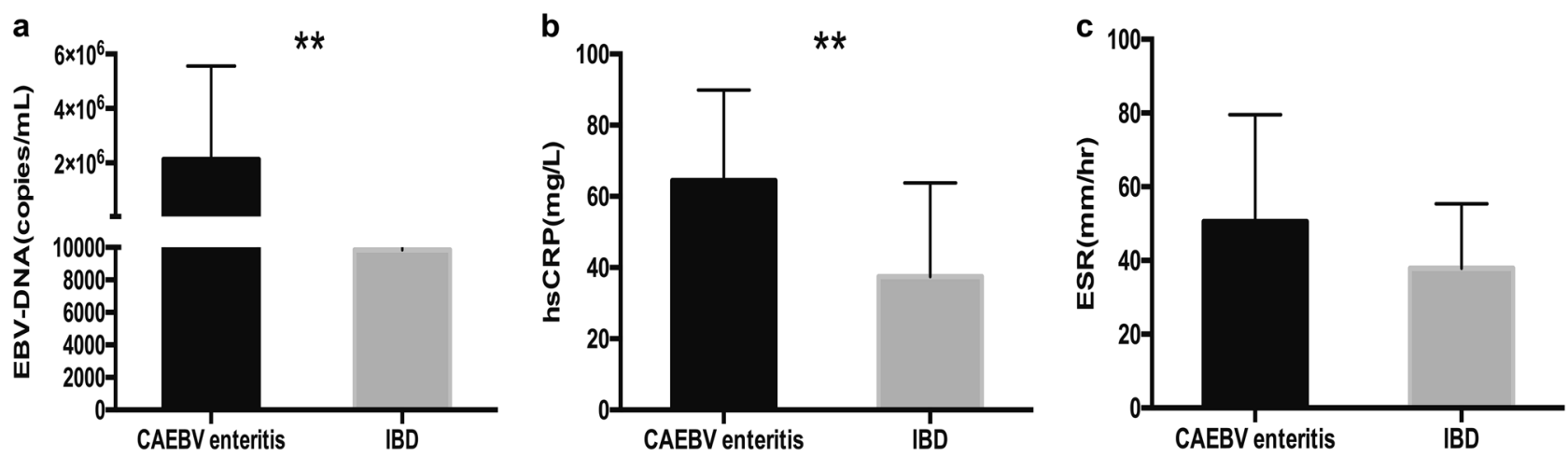

Fig. 1 Laboratory index of chronic active Epstein-Barr virus infective enteritis and inflammatory bowel disease patients. a Serum Epstein-Barr virus load of chronic active Epstein-Barr virus infective enteritis $(N=9)$ and inflammatory bowel disease patients $(N=17)$. b C-reactive protein (CRP) results of chronic active Epstein-Barr virus infective enteritis $(N=10)$ and inflammatory bowel disease patients $(N=61)$. c Erythrocyte sedimentation rate results of chronic active Epstein-Barr virus infective enteritis $(N=9)$ and inflammatory bowel disease patients $(N=55)$. $* * p<$ 0.01 , two-tailed unpaired Student's $t$ test 


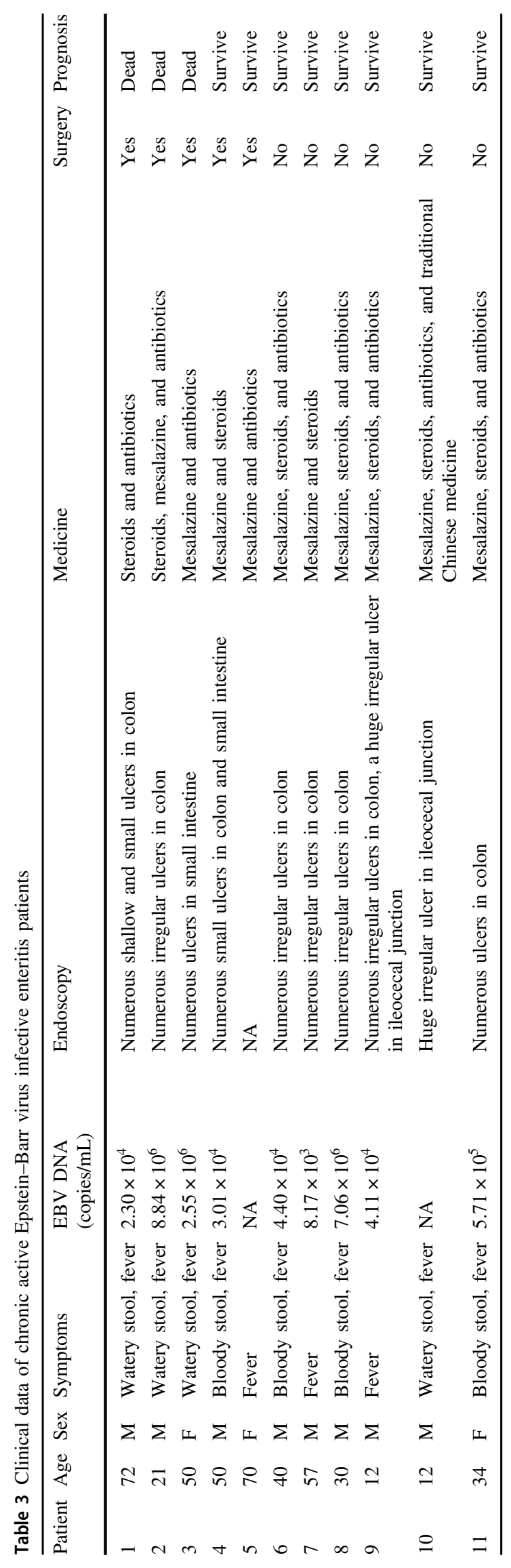

possessed by $\mathrm{CD} 8+\mathrm{T}$ cells. CD56 was negative in all cases. No case was detected by the loss of CD5.

\section{Prognosis}

Three patients died within 5 years of disease onset, so we analyzed the correlation of prognosis with symptoms, Epstein-Barr virus DNA and Epstein-Barr virus antibody, receiving surgery or not. Although no statistically significant correlations were observed, all of the three patients have received total colectomy and two of them have died within 1 month after surgery due to infection and intraabdominal hemorrhage. The 5-year survival rate of the nonsurgical group was $100 \%$ (6/6), while that of the surgical group was $40 \%(2 / 5)$. A larger-scale study is required to further address the prognosis and the association of total colectomy surgery with survival in this disease.

\section{Discussion}

In this study, we report the clinicopathologic characteristics in a unique group of 11 patients with chronic active Epstein-Barr virus infective enteritis and compare the clinical symptoms with inflammatory bowel disease patients. To our best knowledge, this is the first series of chronic active Epstein-Barr virus infective enteritis with systemic symptoms so far. Our results demonstrated considerable heterogeneity among those patients and a strong similarity between chronic active Epstein-Barr virus infective enteritis and inflammatory bowel disease. Increased awareness of chronic active Epstein-Barr virus infective enteritis is important for avoiding misdiagnosis.

In our series, the majority of patients were young to middle-aged, predominantly males, who commonly presented with symptoms of diarrhea and abdominal pain, clinically mimicking inflammatory bowel disease. The enteritis involves both colon and small intestine in most cases, and rare cases with only colon or small intestine involvement.

Among the 11 cases, the common gastrointestinal symptoms are diarrhea, abdominal pain, and hematochezia. The systemic presentations include fever, hepatomegaly, splenomegaly, and lymphadenopathy. Although these symptoms overlap with inflammatory bowel disease, all patients in our study presented with high fever (over $39^{\circ} \mathrm{C}$ ), which is quite distinct from inflammatory bowel disease patients. As for physical signs, hepatomegaly, splenomegaly, and lymphadenopathy are common in chronic active Epstein-Barr virus infective enteritis patients, but they are rare in inflammatory bowel disease patients.

Chronic active Epstein-Barr virus infective enteritis patients also present different endoscopic findings from 
Fig. 2 Shallow and small intestinal ulcers in chronic active Epstein-Barr virus infective enteritis
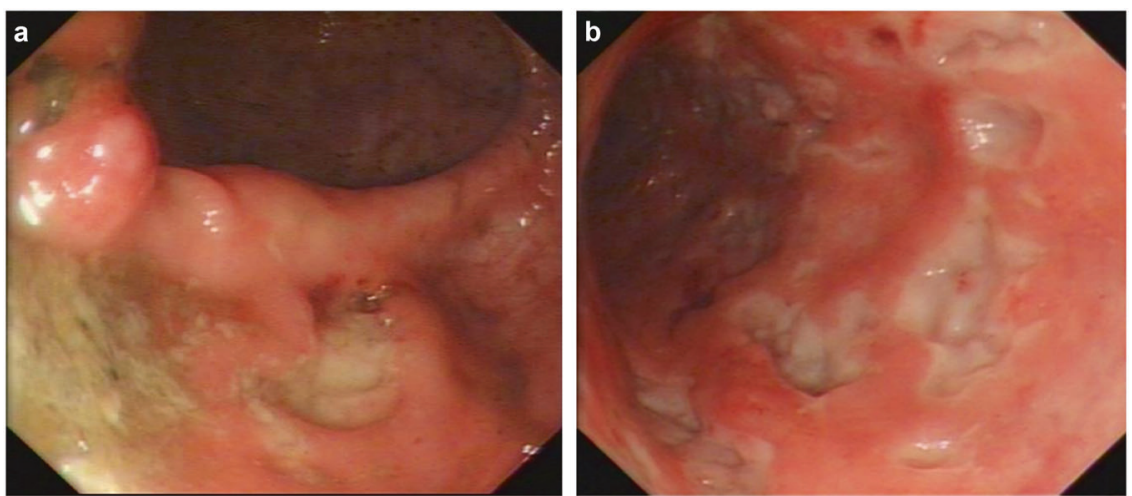

inflammatory bowel disease. We found that the major distortions were numerous shallow, small, and irregular ulcers in both colon and small intestine, but there were no uniform, continuous lesions, cobble-like appearance, and longitudinal ulcers, while in patients with ulcerative colitis, endoscopy typically finds a uniform, continuous inflammation extending proximally from the rectum, but limited to the colon [11]. In contrast with ulcerative colitis, inflammation in Crohn's disease can involve the entire gastrointestinal tract, but the inflamed mucosal areas typically alternate with non-inflamed mucosal surfaces ("skip lesions"). Characteristic configurations including small, deep "aphthous" ulcers or longitudinal, polygonal ("snailtrack") ulcers, and cobblestone-pattern, are often seen in the terminal ileum [11]. Since there are no series cases of chronic active Epstein-Barr virus infective enteritis, only a sporadic case report mentions endoscopic findings [6], and our findings may provide some valuable information for awareness of chronic active Epstein-Barr virus infective enteritis.

Chronic active Epstein-Barr virus infective enteritis has been thought to be linked to viral replication. Virus loads in serum were analyzed in some of the patients. The results showed noticeable increases in viral loads in both serum and intestinal tissue in all the chronic active Epstein-Barr virus infective enteritis patients and serum EBV DNA is more than $10^{5}$ copies/mL, suggesting that quantitative polymerase chain reaction (PCR) analysis of serum for Epstein-Barr virus and in situ hybridization for Epstein-Barr virus-encoded RNA were valuable diagnostic methods, and Epstein-Barr virus DNA of chronic active Epstein-Barr virus infective enteritis is super high. On the contrary, Epstein-Barr virus antibody tests are less useful since positive EBV IgG and negative EBV IgM were found in both chronic active Epstein-Barr virus infective enteritis and inflammatory bowel disease patients. Based on these findings, we recommend that if a patient presented with a series of gastrointestinal symptoms and signs mimicking inflammatory bowel disease but also with high fever, splenomegaly, and hepatomegaly, clinicians should consider viral serologic tests and colonic tissue analysis to determine Epstein-Barr virus presence [12, 13].

Histological features of chronic active Epstein-Barr virus infective enteritis showed mucosal lymphoplasmacytic infiltration and focally disturbed crypt architecture in some cases, which can also occur in ulcerative colitis [11]. Nevertheless, diffuse crypt abnormalities, crypt abscesses, and basal plasmacytosis are not features seen in chronic active Epstein-Barr virus infective enteritis. Histological findings of surgical samples of chronic active Epstein-Barr virus infective enteritis showed Crohn's disease-like features such as transmural inflammation, fissuring ulcers, and lymphoid aggregates in the intestinal wall [14], but chronic active Epstein-Barr virus infective enteritis lacks granulomas and chronic connective tissue changes like neural hypertrophy and thickened muscularis mucosae, which occur more often in Crohn's disease.

Detection of Epstein-Barr virus may be achieved by various methods, including in situ hybridization for Epstein-Barr virus-encoded RNA, immunohistochemistry for latent membrane protein, quantitative PCR assays for BamH1 W and EBNA1, and Epstein-Barr virus serology for early antigen and VCA [15]. Currently, the most sensitive method of detection is the manual in situ hybridization for Epstein-Barr virus-encoded RNA, achieving a sensitivity of virtually $100 \%$ [16], and is currently considered the gold standard for demonstrating Epstein-Barr virus infection. There are no established criteria regarding the percentage of Epstein-Barr virusencoded RNA-positive cells for the definition of active Epstein-Barr virus infection. Some studies employed $10 \%$ as a threshold and others $20 \%$ or ten positive cells/ HPF [17-19]. These conditions could plausibly hamper the accurate determination of whether and to what extent Epstein-Barr virus is involved. Our results showed that all surgery samples had more than $100 \mathrm{EBV}+$ cells/HPF, and all of the biopsy samples were more than $30 \mathrm{EBV}+$ cells/HPF. It provides some evidence to establish the criteria of Epstein-Barr virus positivity definition for future studies. 
The clinicopathologic features of chronic active Epstein-Barr virus infective enteritis

393

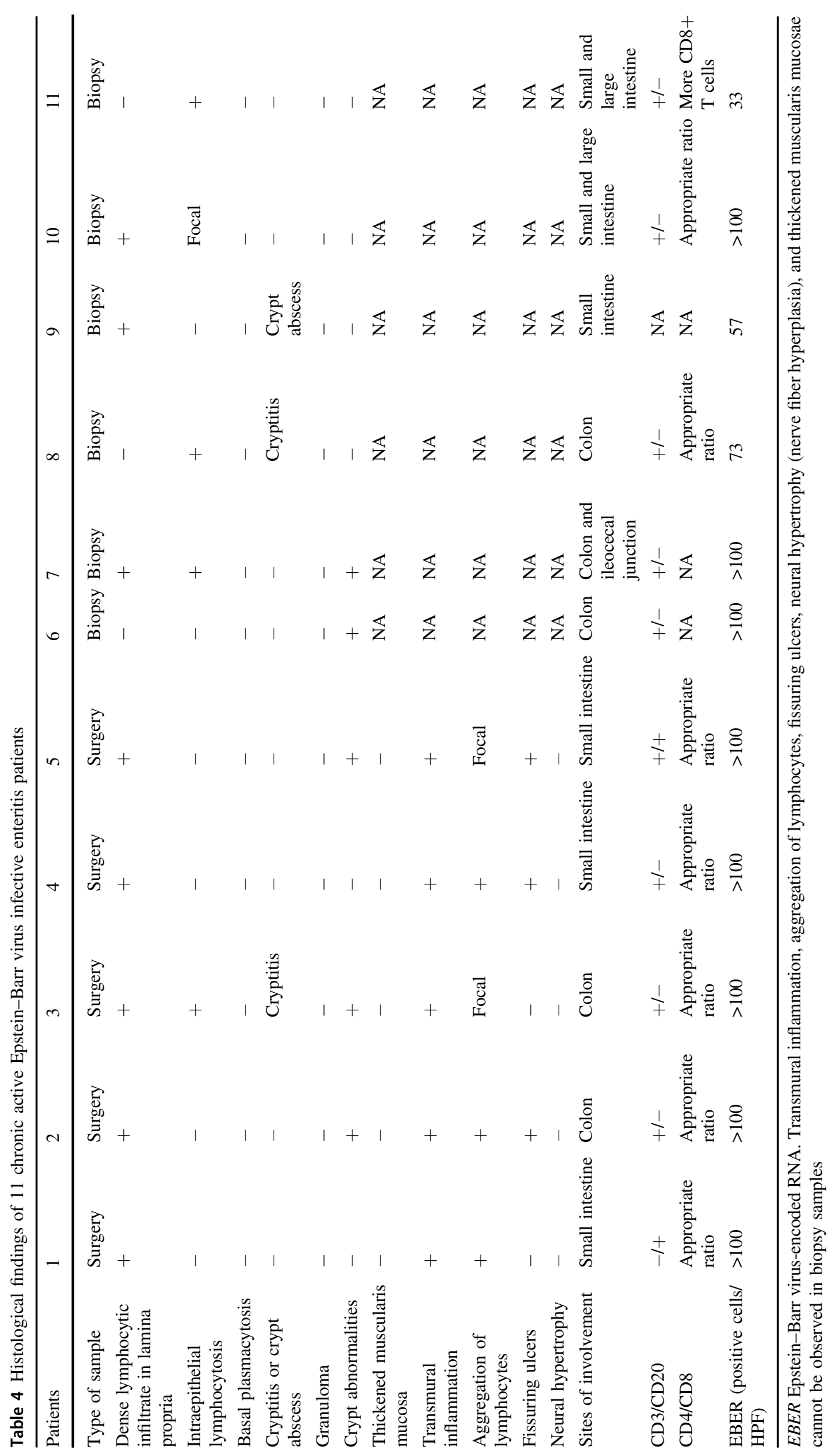

SPRINGER NATURE 
Fig. 3 Histological findings of chronic active Epstein-Barr virus infective enteritis. a Ileal biopsy, transmucosal increase of lymphocytes was observed with lymphoid tissue hyperplasia in submucosa HE $\times 40$. b Increased intraepithelial lymphocytosis $\mathrm{HE}$ $\times 200$. $\mathbf{c}$ This case shows transmural lymphoid aggregates, which occurs more often in Crohn's disease HE $\times 10$.

d Transmural inflammation with fissuring ulcer $\mathrm{HE} \times 10$. e In situ hybridization for Epstein-Barr virus-encoded RNA results showed Epstein-Barr virusencoded RNA-positive lymphocytes in intestinal mucosa $\mathrm{HE} \times 200$
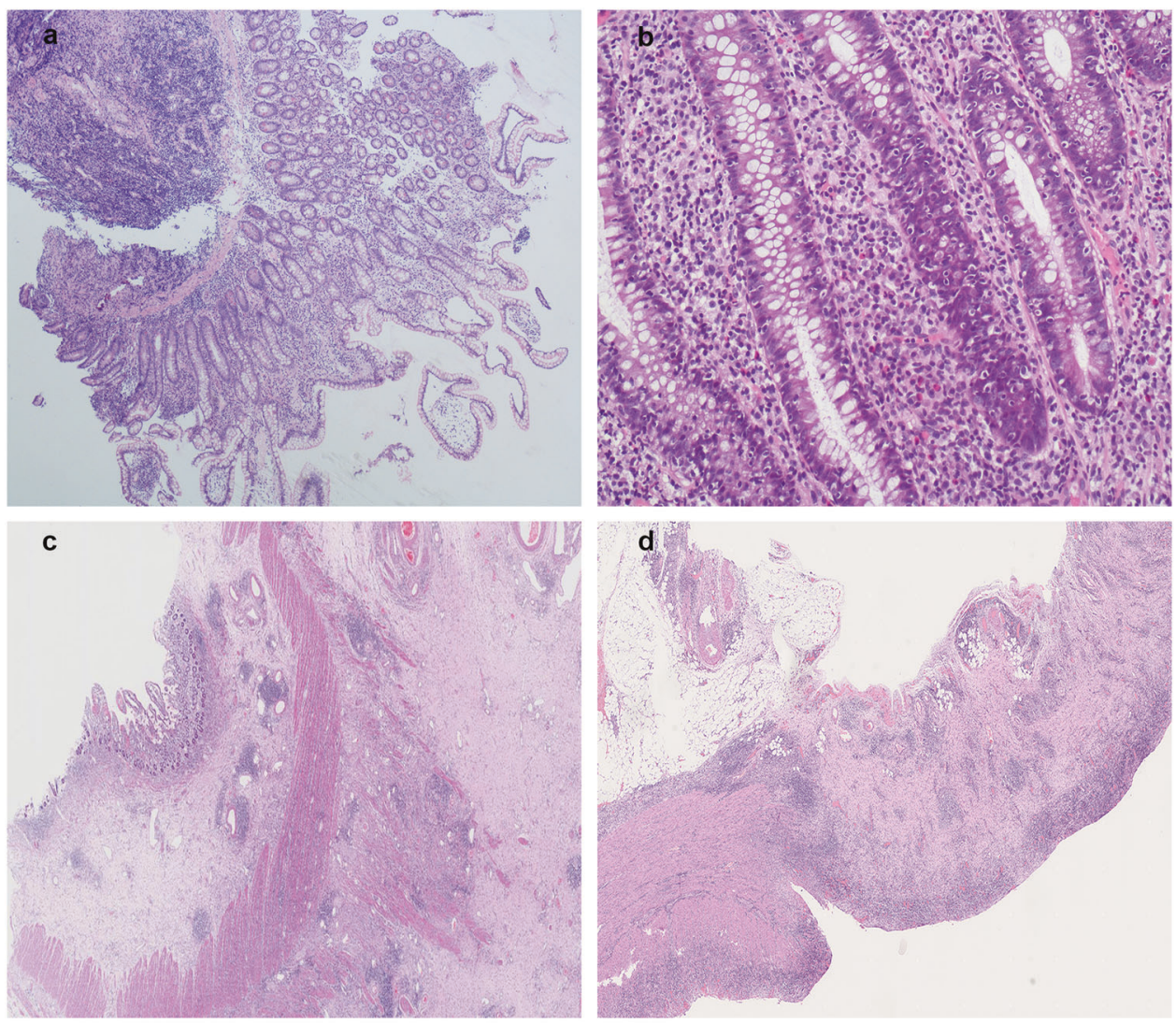

Chronic active Epstein-Barr virus infection often results in a poor prognosis. Allogeneic hematopoietic stem cell transplantation is the only cure, without which patients with chronic active Epstein-Barr virus infection die within several years [20, 21]. In Japan, the average survival year time is 4.3 years, and the long-term ( $>15-$ year) survival rate is less than 20\% [22]. In our study, 3 of 11 patients died within 5 years of disease onset, and 2 of them died within 1 month after surgery due to infection and intra-abdominal hemorrhage. Although no significant prognostic factors were identified due to a small case number, the 5-year survival rate of the nonsurgical group was $100 \%$, while that of the surgery group was $40 \%$. Chronic active Epstein-Barr virus infective enteritis patients with severe disease activity tend to have surgical complications. Therefore, total colectomy in chronic active Epstein-Barr virus infective enteritis patients should be avoided.

This study has several limitations. First, it consists of a relatively small sample size, since chronic active Epstein-Barr virus infective enteritis cases are rare. As such, our findings may not be necessarily generalizable to other populations. Second, it is a retrospective study and therefore does not provide information regarding changes in the immunophenotype of peripheral lymphocytes.

In summary, we reported the clinicopathologic characteristics of 11 patients with chronic active Epstein-Barr virus infective enteritis. Due to the overlapping clinicopathological features, differential diagnosis of chronic 
active Epstein-Barr virus infective enteritis from inflammatory bowel disease poses a clinical challenge. The possibility of chronic active Epstein-Barr virus infective enteritis should be considered for patients who exhibit inflammatory bowel disease-like symptoms with intermittent high fever and showing irregular, small, and shallow ulcers in both colon and small intestine endoscopically. Histopathological and virological examinations, especially in situ hybridization for Epstein-Barr virus-encoded RNA are critical for confirming a diagnosis.

\section{Conclusion}

Clinicopathologic features have been summarized to better recognize chronic active Epstein-Barr virus infective enteritis. There are resemblances between chronic active Epstein-Barr virus infective enteritis and inflammatory bowel disease, but some symptoms, signs, and indexes like intermittent fever, hepatomegaly, splenomegaly, lymphadenopathy, and elevated C-reactive protein, Epstein-Barr virus DNA are characteristics to differentiate chronic active Epstein-Barr virus infective enteritis and inflammatory bowel disease. Histopathological features also help the discrimination. Serum Epstein-Barr virus DNA and intestinal tissue in situ hybridization for Epstein-Barr virusencoded RNA are recommended to exclude chronic active Epstein-Barr virus infective enteritis.

Acknowledgements We kindly thank the following hospital for providing cases: Peking Union Medical College Hospital, Children's Hospital of Fudan University; Xinqiao Hospital, Third Military Medicine University; Rui Jin Hospital of Shanghai Jiao Tong University; The $2^{\text {nd }}$ Affiliated Hospital of Zhejiang University; Bethune $1^{\text {st }}$ Affiliated Hospital of Jilin University; The $1^{\text {st }}$ Affiliated Hospital of Zhejiang University; West China Hospital of Sichuan University; Huashan Hospital of Fudan university.

\section{Compliance with ethical standards}

Conflict of interest The authors declare that they have no conflict of interest.

\section{References}

1. Chang CM, Yu KJ, Mbulaiteye SM, Hildesheim A, Bhatia K. The extent of genetic diversity of Epstein-Barr virus and its geographic and disease patterns: a need for reappraisal. Virus Res. 2009;143:209-21.

2. Cohen JI. Epstein-Barr virus infection. $\mathrm{N}$ Engl $\mathrm{J}$ Med. 2000;343:481-92.

3. Tsuchiya S. Diagnosis of Epstein-Barr virus-associated diseases. Crit Rev Oncol Hematol. 2002;44:227-38.
4. Kimura H, Cohen JI. Chronic active Epstein-Barr virus disease. Front Immunol. 2017;8:1867.

5. Kimura H, Morishima T, Kanegane H, Ohga S, Hoshino Y, Maeda A, et al. Prognostic factors for chronic active Epstein-Barr virus infection. J Infect Dis. 2003;187:527-33.

6. Roth DE, Jones A, Smith L, Lai R, Preiksaitis J, Robinson J. Severe chronic active Epstein-Barr virus infection mimicking steroid-dependent inflammatory bowel disease. Pediatr Infect Dis J. 2005;24:261-4.

7. Zhang Y, Jiang Z, Liu R, Chen H, Wang M, Cao Q. Chronic active Epstein-Barr virus associated enteritis may develop into a precancerous disease. Inflamm Bowel Dis. 2017;23:E19-21.

8. Shi W, Jiang ZN. [Chronic active Epstein-Barr virus enteritis: report of a case]. Zhonghua Bing Li Xue Za Zhi. 2016;45:725-6.

9. Chachu KA, Osterman MT. How to diagnose and treat IBD mimics in the refractory IBD patient who does not have IBD. Inflamm Bowel Dis. 2016;22:1262-74.

10. Gulley ML, Tang W. Laboratory assays for Epstein-Barr virusrelated disease. J Mol Diagn. 2008;10:279-92.

11. Nikolaus S, Schreiber S. Diagnostics of inflammatory bowel disease. Gastroenterology. 2007;133:1670-89.

12. Ito Y, Suzuki M, Kawada J, Kimura H. Diagnostic values for the viral load in peripheral blood mononuclear cells of patients with chronic active Epstein-Barr virus disease. J Infect Chemother. 2016;22:268-71.

13. Sakamoto Y, Mariya Y, Kubo K. Quantification of Epstein-Barr virus DNA is helpful for evaluation of chronic active Epstein-Barr virus infection. Tohoku J Exp Med. 2012;227:307-11.

14. Gomollon F, Dignass A, Annese V, Tilg H, Van Assche G, Lindsay JO, et al. 3rd European evidence-based consensus on the diagnosis and management of Crohn's disease 2016: part 1: diagnosis and medical management. J Crohns Colitis. 2017;11:3-25.

15. Ryan JL, Fan H, Glaser SL, Schichman SA, Raab-Traub N, Gulley ML. Epstein-Barr virus quantitation by real-time PCR targeting multiple gene segments: a novel approach to screen for the virus in paraffin-embedded tissue and plasma. J Mol Diagn. 2004;6:378-85.

16. Humar A, Hebert D, Davies HD, Humar A, Stephens D, $\mathrm{O}^{\prime}$ Doherty $\mathrm{B}$, et al. A randomized trial of ganciclovir versus ganciclovir plus immune globulin for prophylaxis against EpsteinBarr virus related posttransplant lymphoproliferative disorder. Transplantation. 2006;81:856-61.

17. Chang ST, Lu YH, Lu CL, Weng SF, Lin SH, Kuo SY, et al. Epstein-Barr virus is rarely associated with diffuse large B cell lymphoma in Taiwan and carries a trend for a shorter median survival time. J Clin Pathol. 2014;67:326-32.

18. Nissen LH, Nagtegaal ID, de Jong DJ, Kievit W, Derikx LA, Groenen PJ, et al. Epstein-Barr virus in inflammatory bowel disease: the spectrum of intestinal lymphoproliferative disorders. J Crohns Colitis. 2015;9:398-403.

19. Park S, Lee J, Ko YH, Han A, Jun HJ, Lee SC, et al. The impact of Epstein-Barr virus status on clinical outcome in diffuse large Bcell lymphoma. Blood. 2007;110:972-8.

20. Sawada A, Inoue M, Kawa K. How we treat chronic active EpsteinBarr virus infection. Int J Hematol. 2017;105:406-18.

21. Gotoh K, Ito Y, Shibata-Watanabe Y, Kawada J, Takahashi Y, Yagasaki $\mathrm{H}$, et al. Clinical and virological characteristics of 15 patients with chronic active Epstein-Barr virus infection treated with hematopoietic stem cell transplantation. Clin Infect Dis. 2008;46:1525-34.

22. Kimura $\mathrm{H}$. [Chronic active Epstein-Barr virus infection]. Uirusu. 2011;61:163-73. 